\title{
$\mathrm{PH} \mathbf{1 0 2} \boldsymbol{2}_{\text {cosate }}$
}

a debate Comunicación y redes sociales en instituciones culturales

| coordina Candela González Sánchez

\section{El auge del hashtag en el sector cultural durante la pandemia}

Cristina Ortiz Portillo | Secretaría General de la Organización de Estados Iberoamericanos para la Educación, la Ciencia y la Cultura (OEI)

URL de la contribución <www.iaph.es/revistaph/index.php/revistaph/article/view/4799>

Resulta imposible tratar de abordar cómo la cultura y sus instituciones emplean actualmente las redes sociales para comunicar sin mencionar la COVID-19. Este evento ha transformado la manera en que nos relacionamos y comunicamos dentro del ámbito profesional, además de marcar de forma irremediable la agenda en la cultura nacional e internacional.

Es inevitable preguntarse hasta qué punto hemos mutado comunicacionalmente con este virus. En abril de 2020 We are Social y Hootsuite lanzaban Digital 2020, un informe que reflejaba cómo el confinamiento ha aumentado el tiempo que hemos pasado conectados, y que también evidenciaba cómo hemos modificado la manera en la que nos expresamos: con respecto a 2019 escribimos con un 36 \% más de emojis, un mecanismo que posibilita una economía del lenguaje a la vez que aporta mayor expresividad al mensaje. En un momento de nuestras vidas en el que las pantallas han sido espacio de trabajo, relación, ocio y cultura hemos abrazado las formas de expresión que nos permiten comunicarnos mejor.

\section{Comparte cultura y conocimiento con la etiqueta} \#TwitterCultural

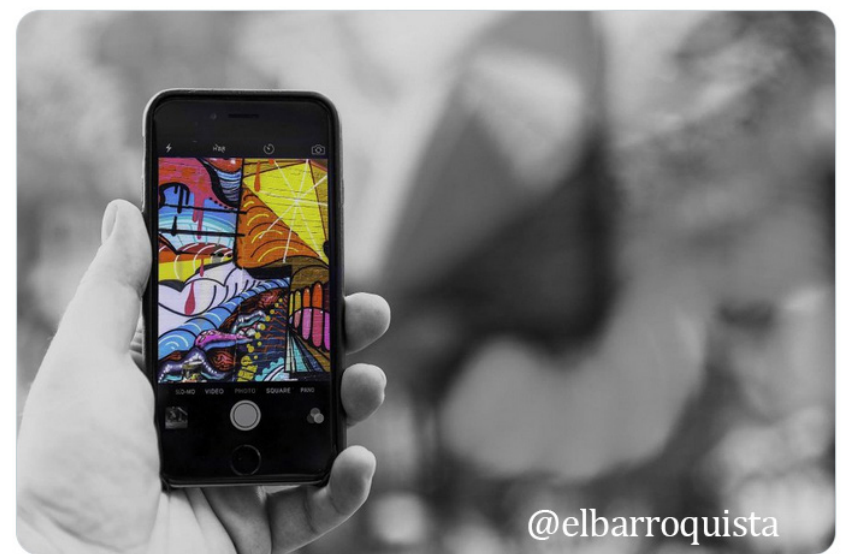

La cultura tomó buena cuenta de este cambio de paradigma. Desde el primer momento del confinamiento, y del correspondiente cierre de espacios culturales, los profesionales de la cultura y las instituciones se trasladaron por completo al plano digital y, más concretamente, a las redes sociales, un espacio accesible y con horario ininterrumpido de consulta que permite la difusión masiva de contenido.

En ese escenario se producía un hecho insólito hasta el momento: la proliferaron a nivel mundial de las campañas impulsadas por los Gobiernos a través de hashtags para que instituciones y profesionales del sector pusieran su contenido cultural a disposición de todos y todas bajo una etiqueta común. La estrategia era clara: del mismo modo que se ganaba visibilidad, se creaba comunidad con los usuarios y estos se alentaban entre ellos al mostrar los distintos contenidos disfrutados durante este periodo. En España compartimos lecturas, películas, música, espectáculos o exposiciones a través del hashtag \#LaCulturaEnTuCasa, en Argentina mediante \#CulturaEnCasa, en países anglosajones lo hicieron por medio de \#CultureAtHome e Italia con \#LaCulturalnCasa.

La respuesta popular fue masiva y a las campañas gubernamentales le siguieron las creadas por las propias instituciones culturales. Estas instituciones y sus profesionales diseñaron hashtags propios dentro de una estrategia para ganar reclamo, visibilidad y como medida para acortar la distancia generada hasta que se produjera la reapertura de los espacios.

Mención especial en este apartado requieren los museos, un sector muy presente en el ámbito digital y que se ha volcado durante los momentos de cierre en el confinamiento. En España, a través de \#PradoContigo el Museo del Prado, con ya una buena comunidad digi- 
tal a la espera, agrupaba actividades online mientras las salas estaban cerradas. El momento ha sido fantástico para que los responsables de la comunicación digital trasladaran historias, poder conocer detalles específicos y acceder a la cultura mediante nuevos mecanismos. Esta medida también era globalizada: al otro lado del Atlántico el teatro Colón de Bogotá compartía su contenido con la etiqueta \#EITelónSigueArriba y el Museo Nacional de Arte de México posteaba en redes sociales \#ContigoEnLaDistancia para ofrecer apoyo y contenidos diversos a todo aquel que lo buscara.

Reforzar la comunidad digital era una de las principales claves para lanzar estas campañas, pero amenizar los tiempos inciertos y apoyar a un sector en crisis formaba parte también del empuje de muchos creadores y personalidades digitales. Un ejemplo es el caso de la cuenta de Twitter @barroquista, que mediante \#TwitterCultural invitó a sus seguidores a llenar esta red social de cultura.

La época de desescalada nos trajo emocionantes campañas de reactivación del tejido cultural y que fomentaban el regreso a los espacios culturales, como \#VolverásAEmoncionArte de los museos de Málaga u otras que trasmitían confianza y defendían que la \#LaCulturaEsSegura.

Al analizar este periodo, se observa que la verdadera revolución se ha producido con el uso de los hashtags como herramienta de presión por parte del sector cultural para que los Gobiernos incorporasen nuevas medidas de apoyo. En este sentido destacan el conocido \#ApagónCultural, que se convirtió en trending topic en España en el mes de abril, o \#AlertaRoja, promovido por la industria internacional de espectáculos y eventos.

Desde instituciones como la Organización de Estados Iberoamericanos para la Educación, la Ciencia y la Cultura (OEI) también hemos sensibilizado sobre los efectos negativos de la pandemia en el sector artístico y cultural, así como reivindicado la protección de los mismos a través de un decálogo cultural que se materializó en redes sociales mediante el hashtag \#TiempoDeCultura.
Podemos afirmar que 2020 ha supuesto un hito no solamente en el empuje de digitalización que ha arrastrado a todos los sectores y especialmente al cultural, también para las narrativas. Los hashtags, que nacieron como etiquetas para agrupar contenido y como lugares virtuales de conversación, se han transformado en un verdadero espacio de llamada y reivindicación a raíz del coronavirus. Queda por ver si esta tendencia se convertirá en norma, pero hoy día cuesta pensar en una campaña que no tenga su propio lema precedido de la almohadilla.

\section{BIBLIOGRAFÍA}

- Chiorboli, D. (2020) En cuarentena: cuáles son los emojis más utilizados durante la pandemia. We are social, 29 de mayo de 2020. Disponible en: https://wearesocial.com/es/ blog/2020/05/cuales-son-los-emojis-mas-utilizados-durante-lapandemia [Consulta: 08/12/2020]

- Digital 2020 April Global Statshot Report (2020) sl: We are Social; Hootsuite, Published on Apr 23, 2020. Disponible en: https://www.slideshare.net/DataReportal/digital-2020april-global-statshot-report-april-2020-v01?ref=https://s3ap-southeast-1.amazonaws.com/datareportal/digital/2020/ wearesocial/en/digital-2020-wearesocial-en-q2-global-digitalstatshot.htm [Consulta: 08/12/2020]

- Ministerio de Cultura y Deporte de España (2020) Campaña "La cultura en tu casa", 18/03/2020. Disponible en: http://www. culturaydeporte.gob.es/actualidad/2020/03/laculturaencasa. html [Consulta: 08/12/2020]

- Museo del Prado (2020) Proyecto El Prado contigo. Desde el 12 de marzo hasta el 5 de junio de 2020. Disponible en: https:// www.museodelprado.es/recurso/el-prado-contigo/894ec21c8ba2-a39b-30a9-b4859670eeb1 [Consulta: 08/12/2020]

- Radio Televisión Española (2020) Coronavirus \#AlertaRoja: el sector del espectáculo se moviliza para denunciar que está "al borde del colapso" por la COVID, 17 de septiembre de 2020. Disponible en: https://www.rtve.es/noticias/20200917/alertarojasector-del-espectaculo-se-moviliza-para-denunciar-esta-bordedel-colapso-covid/2042446.shtml [Consulta: 08/12/2020] 